\title{
Avaliação do Suporte de TDIC na Formação do Pedagogo. Um Estudo em Universidade Brasileira
}

\section{Assessment of DICT Resource in Pedagogic Undergraduate. A Study in a Brazilian University}

\author{
Francisco César Martins da Silva * \\ Alberto Sampaio Lima \\ Wagner Bandeira Andriola \\ Universidade Federal do Ceará
}

\begin{abstract}
Entre os fatores que influem na atuação de um professor do ensino básico, pode-se destacar a sua formação inicial e as condições de trabalho. O suporte pedagógico através do uso das tecnologias digitais de informação e comunicação (TDIC) é um dos fatores que podem influenciar na produtividade e no sucesso dos professores. Entretanto, foi identificado que muitos professores do ensino básico Brasileiro não estariam aptos a utilizar as TDIC em sua atuação profissional. Diante desse contexto, o presente trabalho teve como objetivo analisar o uso das TDIC e seus impactos na formação do pedagogo. Foi realizado um estudo de caso no curso de pedagogia da Universidade Federal do Ceará, Brasil, onde foram confrontadas as visões de professores e alunos. Os resultados obtidos indicaram existir uma divergência entre a visão do professor e dos alunos em relação à formação atual do pedagogo para o uso de novas tecnologias no curso avaliado. Os resultados obtidos podem subsidiar uma reflexão sobre a forma como as novas tecnologias devem ser abordadas durante a graduação do pedagogo.
\end{abstract}

Palavras-chave: Práticas pedagógicas, Ensino na graduação em pedagogia, Avaliação do ensino e aprendizagem, Tecnologias digitais de informação e comunicação.

\begin{abstract}
Among the factors that influence the performance of a teacher of primary school, we can highlight their initial training and working conditions. The pedagogical support through the use of digital information and communication technologies (DICT) is one of the factors that can influence the productivity and success of teachers. However, it was identified that many teachers of the Brazilian basic education are not able to use the DICT in their professional performance. In this context, this study aimed to analyze the use of DICT and its impact on the formation of the pedagogue. A case study was carried out in the course of pedagogy at the Federal University of Ceará, Brazil, where the views of teachers and students were confronted. The results indicated there is a divergence between the teacher and students' views regarding the current teacher training for the use of new technologies in assessed course. The results can support a reflection on how new technologies should be addressed during the graduation.
\end{abstract}

Keywords: Pedagogical practices, Pedagogic undergraduate teaching, Teaching and learning evaluation, Digital information and communication technologies.

\footnotetext{
*Contacto: profcesarmartins2012@gmail.com

ISSN: $1696-4713$

www.rinace.net/reice/

revistas.uam.es/reice

$\begin{array}{ll}\text { Recibido: } & 29 \text { de junio } 2015 \\ 1^{\text {a }} \text { Evaluación: } & 13 \text { de septiembre } 2015 \\ 2^{\text {a }} \text { Evaluación: } & 23 \text { de enero } 2016 \\ \text { Aceptado: } & 23 \text { de marzo } 2016\end{array}$
}




\section{Introdução}

A educação básica fornece suporte para a formação da nova sociedade brasileira, posto que cada vez mais se torna necessário a melhoria de qualidade na formação do aluno do ensino básico. Catapan e outros (2012) afirmam que um olhar sistemático para os procedimentos utilizados na educação e a qualidade do ensino contribui para a promoção de mudanças e para o desenvolvimento da sociedade. A partir desse contexto, percebe-se a necessidade de se refletir sobre as competências e habilidades necessárias na formação do futuro professor da educação básica, acerca do uso pedagógico das tecnologias digitais de informação e comunicação (TDIC). Para se buscar a inovação como ferramenta para o desenvolvimento e melhoria das Instituições de Ensino Superior (IES), torna-se absolutamente necessário a busca e posterior adoção de práticas de ensino inovadoras (Castro, 2012).

Lima e Andriola (2013) afirmam que o relato de práticas pedagógicas inovadoras tem ajudado os docentes das IES, contribuindo para a melhoria do ensino de graduação, através da obtenção de melhores resultados no processo de ensino e aprendizagem. Morales (2010) afirmou que existe uma desconexão entre a pesquisa e a prática na educação, já que existe interesse crescente dos professores em pesquisar sobre o processo de aquisição de conhecimento que envolve professor e alunos. Sánchez Ramón (2005) afirma que existe uma dificuldade ao se abordar o tema inovação na educação, pois o que hoje se considera como inovação pode vir a não ser nos próximos anos, por conta da rápida evolução e da dinamicidade das IES.

Entre as principais dificuldades identificadas na pesquisa de Da Silva (2013) sobre a utilização das TDIC por professores do ensino fundamental em Brasília, foram identificadas as seguintes dificuldades: falta de conhecimento em manusear os equipamentos, o quantitativo de equipamentos insuficientes para todos os professores e a informatização dos métodos clássicos de ensino.

Um dos pontos que motivaram a realização do presente estudo surgiu a partir de observações empíricas durante formações realizadas com professores do ensino fundamental, onde se percebeu a falta de habilidades de muitos professores no manuseio do computador e de ferramentas de software.

$\mathrm{O}$ objetivo geral desta pesquisa foi analisar o curso de licenciatura em pedagogia da Universidade Federal do Ceará (UFC) no âmbito do processo ensino aprendizagem, através da percepção do professor e do aluno. Os objetivos específicos foram: examinar o projeto pedagógico do curso de pedagogia da UFC, a fim de identificar as concepções que norteiam a formação do licenciando em pedagogia e o uso pedagógico das TDIC; comparar as percepções dos discentes e docentes sobre o contexto de ensino e aprendizagem do curso de pedagogia da UFC e averiguar, na visão dos alunos e professores do curso de pedagogia da UFC, se a prática dos docentes do curso de pedagogia da UFC favoreceria o desenvolvimento de habilidades e competências necessárias para a formação de professores aptos para a prática pedagógica com o uso das tecnologias digitais.

Visando avaliar a problemática apresentada, foi realizado um estudo de caso no curso de Licenciatura em Pedagogia da Universidade Federal do Ceará (UFC), no intuito de capturar a percepção do professor e do aluno em relação ao processo de ensino e aprendizagem de TDIC na formação do pedagogo. 


\section{Revisão de literatura}

O percurso de formação de professores no Brasil pode ser dividido em seis períodos, conforme Saviani (2009): $1^{\circ}$ período: Ensaios intermitentes de formação de professores (1827-1890); $2^{\circ}$ período: Estabelecimento e expansão do padrão das escolas normais (1890-1932); $3^{\circ}$ período: Organização dos Institutos de Educação (1932- 1939); $4^{\circ}$ período: Organização e implantação dos Cursos de Pedagogia e de Licenciatura e consolidação do modelo das escolas normais (1939-1971); $5^{\circ}$ período: Substituição da Escola Normal pela Habilitação Específica de Magistério (1971-1996) e $6^{\circ}$ período: Advento dos Institutos Superiores de Educação e das Escolas Normais Superiores (1996-2006).

O Parecer n ${ }^{\circ}$ 161/1986 do Conselho Federal de Educação reformulou os cursos de pedagogia Brasileiros, facultando a esses ofertar também a formação para a docência de $1^{\mathrm{a}}$ a $4^{\mathrm{a}}$ séries. Os cursos de pedagogia no Brasil ainda passaram por duas reformas curriculares: a primeira concluída em 1993 e a segunda em 2007.

De acordo com Saviani (2009), foram configurados dois modelos para formação de professores: (a) modelo dos conteúdos culturais-cognitivos e (b) modelo didáticopedagógico. O primeiro modelo configura que a formação do professor finda na cultura geral e no domínio especifica dos conteúdos da área de conhecimento conforme a disciplina que irá lecionar. $\mathrm{O}$ segundo modelo se contrapõe ao seu antecessor, considerando que a formação do professor propriamente dita só se completa com o efetivo preparo pedagógico-didático.

Para Saviani (2009), no Brasil, especificamente nas universidades e no ensino secundário (atual ensino médio), prevalece o modelo dos conteúdos culturais-cognitivos devido à prevalência do Estado, havendo, no entanto, em alguns casos, a autonomia da comunidade acadêmica onde se prevalece o modelo didático-pedagógico.

No limiar do século XXI, a formação de professores enfrenta um novo desafio: o ensino com suporte das tecnologias digitais (Botello et al., 2015). A partir desta constatação, o governo federal brasileiro, através do seu ministério de educação (MEC), vem investindo nas tecnologias digitais. Contudo, o uso desses recursos no espaço escolar requer uma metodologia de ensino e uma formação docente específica, a partir dos cursos de licenciatura ofertados na universidade. Em vista disso, o ideal é que os futuros professores devessem adquirir competências e habilidades para lidar com as tecnologias digitais já disponibilizadas nas escolas públicas.

No entanto, observa-se no exercício da docência do professor a sua exclusão digital (Almeida, 2004). Borges Neto (1998) já explicitava que o professor regente de sala de aula não precisa ser um expert em tecnologias para utilizá-las. Trabalhar com tecnologia é considerá-la como aliada para a transposição didática dos conteúdos elaborados que são necessários para a formação de um novo indivíduo (Bustamante, 2010).

A regulamentação brasileira mais recente que trata da formação de professores para o uso das tecnologias é evidenciada a partir da Resolução CNE/CP 1/2002, que institui as Diretrizes Curriculares Nacionais para a Formação de Professores. Em seu Art. $2^{\circ}$ inciso VI a lei declara a necessidade do preparo para "o uso de tecnologias da informação e da comunicação e de metodologias, estratégias e materiais de apoio inovadores". 
Não se trata de oferecer formação básica de conhecimento de uma determinada tecnologia, como por exemplo, o computador, mas proporcionar condições acadêmicas para a construção do conhecimento usando as ferramentas tecnológicas digitais como apoio (Almeida, 2004; Valente et al., 2003).

O suporte das TDICs para a atuação de professores abrange várias áreas de conhecimento. Kruger (2006) realizou um estudo sobre a necessidade de uso de editores de música, portais e educação à distância na formação musical. $\mathrm{O}$ autor reafirmou a necessidade de maior capacitação tecnológica para os educadores musicais. O trabalho de Maia e Barreto (2014) avaliou a formação oferecida pelo curso de pedagogia da Universidade Estadual do Ceará (UECE) para o ensino de matemática, com o suporte das TDIC.

Durante o trabalho realizado por Freitas e Leite (2013), foram acompanhadas diversas escolas que se abrem a atividades pedagógicas que buscam mesclar a utilização de recursos tecnológicos (como o portátil e a internet) a outros amplamente conhecidos (como o quadro e o giz), intercalando, e algumas vezes integrando o tradicional e o novo. A partir dos resultados, os autores consideram que o fato de entregar uma máquina de grandes recursos ao docente que atua em uma escola não é simples, nem o fará, de um momento para outro, sentir-se seguro para sua utilização em suas atividades pedagógicas.

Freitas e Leite (2013) afirmam que a tecnologia hoje é parte indissociável da sociedade. Para Rosa (2014) o uso das TDIC no ensino é resultante do processo que envolve a chamada sociedade da informação, em que se podem ver, claramente, formas de democratizar a educação para inserir as pessoas digitalmente e ampliar seus letramentos.

Rodrigues (2012) avaliou a utilização das tecnologias digitais como apoio nas aulas de cálculo em uma IES. Os resultados indicaram que o uso das TDIC auxilia no processo ensino aprendizagem, permitindo maior organização do conteúdo a ser ministrado, maior motivação por parte dos docentes e discentes, maior interação e comunicação, além da criação de nova dinâmica nas atividades desenvolvidas.

A partir dos resultados de um estudo de caso em uma escola construtivista, Costa e outros (2013) afirmam que a utilização das TDIC no processo de ensino e aprendizagem e os fundamentos da prática construtivista ultrapassam os conhecimentos construídos na escola. Foram avaliadas ferramentas tecnológicas como o ambiente virtual de aprendizagem Moodle e a rede social Facebook.

\section{Estudo de caso}

Em relação às competências e habilidades a serem construídas pelos licenciados em pedagogia da UFC, o PPC do curso avaliado destaca: a compreensão da dinâmica da realidade; a capacidade crítico-reflexiva sobre sua prática; o empenho no aprimoramento profissional; o reconhecimento do impacto das novas tecnologias para a construção da cidadania e de renovação de sua prática pedagógica; a identificação dos processos pedagógicos desenvolvidos na prática social tangível de ocorrências nas diversos modelos de instituições de ensino (escolares e não escolares), bem como nos movimentos sociais; e o desenvolvimento de consciência profissional e política com relação a atribuição da escola e do educador no meio cultural. 
O perfil necessário à docência, conforme o PPC do curso de Licenciatura em Pedagogia da UFC, é constituído por três elementos-chave: a competência intelectual e técnica, a criatividade e a consciência profissional e política. A tabela 1 ilustra os eixos temáticos presentes no PPC do curso de Licenciatura em Pedagogia da UFC e percentual de carga horária do curso.

Tabela 1. Eixos temáticos com total e percentual de carga horária

\begin{tabular}{lcc}
\hline \multicolumn{1}{c}{ EIXOS TEMÁTICOS } & CARGA HORÁRIA & \% \\
\hline I. Educação e Leitura de Mundo & 784 & 24,5 \\
II. Práxis Educativa e Produção do Conhecimento & 224 & 7,0 \\
III. Gestão de Sistemas e Espaços Educativos & 288 & 9,0 \\
IV. Trabalho Pedagógico e Aprendizagens & 656 & 20,5 \\
V. Atividades Formativas integradoras & 1024 & 32,0 \\
Disciplinas livre/optativas & 112 & 3,5 \\
Atividades complementares & 112 & 3,5 \\
\hline Total & 3.200 & 100 \\
\hline
\end{tabular}

Fonte: PPC/UFC.

Em relação às disciplinas que tratam do ensino com o uso das TDIC, essas estão alocadas no terceiro eixo temático: Trabalho pedagógico e aprendizagem. A tabela 2 mostra os valores percentuais dessas disciplinas em relação à carga horária mínima exigida para o curso, ou seja, 3.200 horas.

Tabela 2. Eixo temático 4

\begin{tabular}{lcc}
\hline \multicolumn{1}{c}{ DISCIPLINAS } & $\mathbf{C} / \mathbf{H}$ & $\mathbf{\%}$ \\
\hline Informática educativa & 64 & 2,0 \\
Educação à distancia & 48 & 1,5 \\
Educação estética & 48 & 1,5 \\
Linguagem e Código & 80 & 2,5 \\
Letramento e alfabetização & 48 & 1,5 \\
Matemática do Ensino Fundamental & 80 & 2,5 \\
Prática na docência no Ensino Fundamental: anos iniciais & 32 & 1,0 \\
Avaliação do ensino aprendizagem & 48 & 1,5 \\
Ciências do Ensino Fundamental & 80 & 2,5 \\
Geografia e História do Ensino Fundamental & 80 & 2,5 \\
Língua Brasileira de Sinais & 48 & 1,5 \\
\hline Total & 656 & 20,5 \\
\hline Fonte: PPC/UFC.
\end{tabular}

Fonte: PPC/UFC.

O eixo 4 apresentou uma parcela percentual de 20,5\% do valor total da carga horária do curso. Dentro desse valor, calculou-se o valor percentual das disciplinas que envolvem as tecnologias, apresentando os seguintes resultados: a disciplina Informática Educativa apresentou 2,0\% enquanto a disciplina Educação à distância apresentou 1,5\%, perfazendo $3,5 \%$ o valor total das disciplinas que envolvem o uso das tecnologias. Comparando esses valores encontrados com os resultados obtidos na pesquisa de Gatti e Barreto (2009), faz-se a inferência de que as disciplinas obrigatórias que envolvem o uso das tecnologias do curso de pedagogia da UFC são superiores aos resultados encontrados pelas pesquisadoras que foi de $0,7 \%$ para as disciplinas obrigatórias de uso das tecnologias digitais, assim como também das disciplinas optativas que foi de 3,2\%. Portanto, em relação à quantidade de disciplinas obrigatórias que utilizam as tecnologias como instrumento pedagógico o curso está acima, em percentual de carga horária, das demais instituições brasileiras envolvidas no estudo das pesquisadoras (Coracini, 2010). 
$\mathrm{O}$ estudo de caso realizado incluiu uma pesquisa quali-quantitativa, onde se utilizou dados para sua explanação, uso da documentação indireta, através da pesquisa bibliográfica e pesquisa documental. A técnica de coleta de dados incluiu a aplicação de um questionário com questões de caracterização do respondente e um conjunto de itens medidos na escala de Likert com 5 categorias de medida. A escala adotada foi a escala de Likert, devido a suas características de reconhecer: a oposição entre contrários, gradiente e situação intermediária e também devido a relação que provoca entre a precisão e a acurácia da mensuração. Houve também a observação simples das aulas de disciplinas onde foram aplicados os questionários. Os dados foram analisados e interpretados através de técnicas de estatística descritiva (análise fatorial), utilizando o programa de computador SPSS. Para resolver as questões de oposição dos contrários bem como a oposição semântica implícita na escala de Likert devido a presença do ponto médio, a pesquisa se utilizou da adaptação da teoria do diferencial semântica de Osgood (1957), Pereira (2004), Sampieri, Collado e Lucio (2013), o referencial semântico de Osgood é uma série de adjetivos extremos que qualificam o objeto de atitudes para os quais se pede reação dos sujeitos. Ou seja, ele qualifica o objeto a partir de um conjunto de adjetivos bipolares.

Os atores da pesquisa foram divididos em dois grupos: grupo dos alunos e grupo dos professores (os coordenadores do curso foram incluídos nesse grupo).

\subsection{Instrumentação}

Foi realizado um pré-teste com o professor da disciplina Informática na Educação do turno noturno ( $3^{\circ}$ semestre), onde houve uma recepção bem-sucedida. O pré-teste foi aplicado no mês de maio de 2014. Participaram do pré-teste o professor da disciplina e treze alunos do curso de licenciatura em pedagogia da UFC.

$\mathrm{O}$ instrumento de pesquisa foi desenvolvido com perguntas mistas (abertas e fechadas), apresentando duas partes: a primeira constava da caracterização do perfil do docente (informações pessoais, formação acadêmica e tempo de serviço no ensino superior, bem como sobre o uso das TDIC na sala de aula) e do discente (informações pessoais e situação acadêmica); a segunda parte estava disposta numa escala de avaliação da formação do licenciando em pedagogia no uso das Tecnologias Digitais de Informação e Comunicação (TDIC), constituída por 30 itens, distribuídos em três eixos: conteúdo, metodologia de ensino e avaliação. A escala de medidas de Likert inicialmente, estava disposta em três categorias: $\mathrm{NC}=$ Não Concordo; $\mathrm{CP}=$ Concordo Parcialmente; $\mathrm{CT}=$ Concordo Totalmente. A escala adotada inicialmente foi modificada após o pré-teste, em função da a escala de Likert com cinco categorias ser mais adequada do que a escala de três e a de sete (Vieira, 2009). A partir da análise desse estudo e dos resultados do préteste, houve a alteração do número de respostas de três para cinco.

A segunda parte do questionário foi reorganizada na escala de avaliação da formação do licenciando em pedagogia no uso das Tecnologias Digitais de Informação e Comunicação (TDIC), alterando-se a quantidade de itens para 23. O questionário incluiu sete questões de caracterização, numa escala de avaliação da formação do licenciando em pedagogia, no uso das Tecnologias Digitais de Informação e Comunicação (TDIC), constituída pelos 23 itens apresentados na tabela 3, medidos numa escala de Likert com cinco categorias: $0=$ Discordo fortemente; $1=$ Discordo; $2=$ Não discordo e nem concordo; 3 = Concordo; $4=$ Concordo fortemente. 
Tabela 3. Itens do cuestionario

\section{ITENS}

E1 A estrutura curricular do curso contempla a articulação da teoria com a prática do futuro professor e as novas tecnologias.

E2 É importante que o futuro professor adquira habilidades necessárias para trabalhar com as novas tecnologias na educação.

E3 Os laboratórios do campus possuem infraestrutura necessária para trabalhar pedagogicamente com as TDIC.

E4 As disciplinas da Matriz Curricular atendem os objetivos do curso que buscam o trabalho com as TDIC.

E5 O Projeto Pedagógico do Curso (PPC) incentiva a integração das TDIC no currículo.

E6 Adquirir habilidades necessárias para trabalhar com as TDIC são importantes, pois oferece grandes benefícios para a formação dos alunos.

E7 O futuro professor deve aprender a utilizar as ferramentas básicas de informática, possibilitando o desenvolvimento de habilidades para o enriquecimento da Prática Pedagógica.

E8 Os alunos são esclarecidos sobre a importância de se trabalhar com as novas tecnologias.

E9 As aulas são dinâmicas com o uso das mais diversas mídias (impressa, TV, rádio e computador).

E10 As aulas são enriquecidas com o uso dos recursos pedagógicos da Internet.

E11 O corpo docente mostra-se sensível ao uso das TDIC na sua prática pedagógica, fazendo uso dela no seu dia a dia acadêmico.

E12 O corpo docente está bem preparado para usar as TDIC como recurso para as atividades de ensino e aprendizagem na educação básica.

E13 O trabalho docente do curso é voltado para o uso das tecnologias digitais livres.

E14 No curso, o software livre tem um papel cada vez mais importante nas estratégias de uso pedagógico com as TDIC.

E15 Os alunos do curso são avaliados processualmente com relação ao uso das TDIC na educação.

E16 O processo formativo contempla a integração com as escolas públicas de ensino básico para o uso pedagógico das TDIC.

E17 O curso relaciona as políticas públicas governamentais que são direcionadas ao uso pedagógico das TDIC com seu PPC, propiciando ao aluno habilidades necessárias para trabalhar com essas ferramentas.

E18 O curso contribui na elaboração de instrumentos de avaliação do ensino-aprendizagem com uso das TDIC para educação básica.

E19 A instituição possui um plano estratégico para o uso das TDIC como ferramenta pedagógica.

E20 A instituição preocupa-se com os benefícios do uso das TDIC no currículo.

E21 Os objetivos do curso apresentam coerência com o perfil profissional do egresso com relação ao uso pedagógico das TDIC.

E22 As TDIC disponíveis para o processo ensino aprendizagem permitem executar o PPC de forma satisfatória.

E23 A instituição preocupa-se com o trabalho docente levando em conta os benefícios do uso das TDIC na sua prática pedagógica.

Fonte: Elaboração própria.

\subsection{População e amostra}

A população foi constituída por 394 alunos do curso de licenciatura em pedagogia da UFC, conforme citado anteriormente. A determinação do tamanho da amostra levou em consideração que para realizar uma análise fatorial, o tamanho da amostra teria que ter, como regra geral, pelo menos cinco vezes mais participantes do que o número de itens da escala a serem analisados, conforme cita Hair e outros (2006). A amostra trabalhada foi de 127 participantes, sendo 118 alunos e 9 professores. A escolha dos participantes aconteceu através da amostragem não-aleatória, incluindo os alunos matriculados do $5^{\circ}$ ao $10^{\circ}$ semestre, pelo fato dos mesmos já terem cursado a disciplina de Informática na 
educação e Educação à distância, as quais são ministradas nos $2^{\circ}$ e $3^{\circ}$ semestres respectivamente (matriz do curso diurno) e nos $3^{\circ}$ e $4^{\circ}$ semestres (matriz do curso noturno), como mostrado na Figura 1. A amostra ainda incluiu os professores, para perceber as concepções que permeiam o trabalho com as TDIC na formação de futuros professores, através da análise de suas propostas e implementações e os coordenadores do curso, para identificar as diferenças ocorridas com a intervenção das TDIC no ensino.

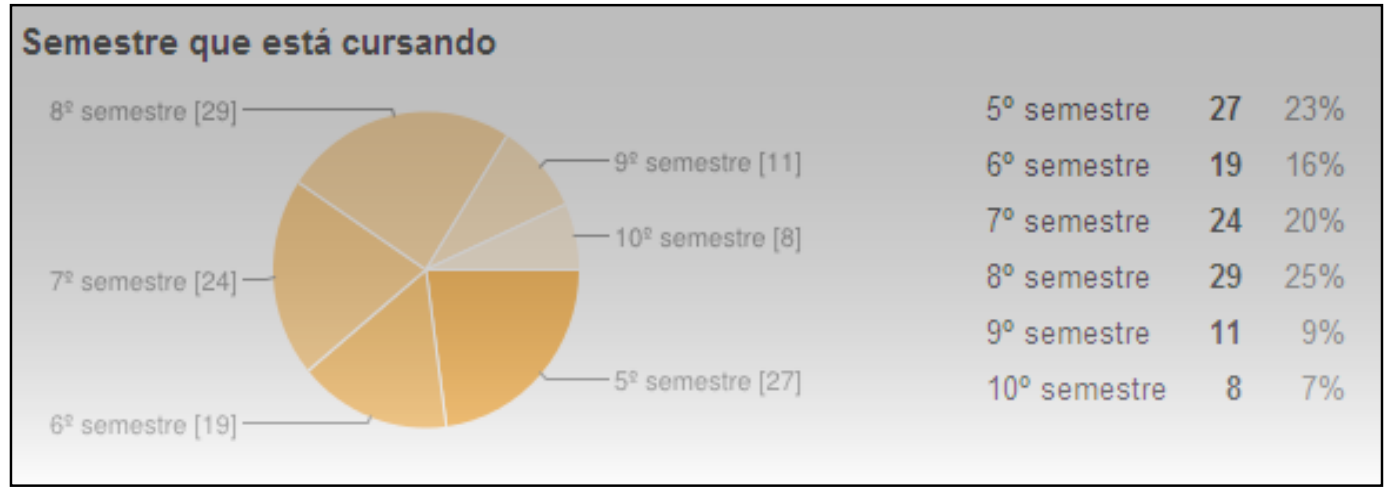

Figura 1. Amostra dos alunos por semestre

Fonte: Elaboração própria.

\subsection{Planejamento do estudo}

Face à natureza da investigação avaliativa, que aborda as opiniões de discentes acerca da atuação dos seus professores, empregou-se na avaliação do docente pelos discentes o método ex post-facto, conforme apregoa Bisquerra Alzina (2004), também conhecido como método estatístico (Carlos Gil, 1999) ou método correlacional (Kerlinger et Lee, 2002).

O estudo de caso realizado seguiu os seguintes passos:

- Validação da problemática através de entrevistas com professores e profissionais da área.

- Revisão de literatura.

- Aplicação do pré-teste.

- Validação do instrumento de pesquisa.

- Aplicação dos questionários.

- Tabulação e análise dos resultados.

- Publicação dos resultados.

\section{Análise dos resultados}

\subsection{Validade de conteúdo da escala de avaliação}

Os dados referentes à escala de avaliação foram escoriados e se construiu um escore total na escala, que pode variar de 0 a 92. A análise dos dados envolveu: a) análise métrica da escala de avaliação calculando o coeficiente de precisão (Alfa de Cronbach) por ser uma 
medida de consistência interna (Vieira, 2009), o erro padrão da medida, o coeficiente de sensibilidade e o teste T2 de Hotelling para verificar a ocorrência de "efeito de halo" no conjunto das respostas aos itens da escala. Foram calculadas as médias das distribuições dos escores em cada item, o coeficiente de variação dessas distribuições e o coeficiente de discriminação dos itens, considerando-se adequados os itens com coeficiente de discriminação positivo igual ou maior que 0,20 ; b) a determinação da validade de conteúdo da escala de avaliação foi feita através da análise fatorial, método dos componentes principais com rotação Varimax. Os valores extraídos também foram escoriados.

Para realização da análise fatorial foi verificada inicialmente a adequação da amostra em função das variáveis (itens) medidas pela escala, no caso 23 itens. Obteve-se a medida de adequação da amostra de Kaiser-Meyer-Olkin, KMO=0,909, muito boa. Em seguida, através do teste de esfericidade de Bartlett, se obteve qui-quadrado igual 1567,913 significativo para $\mathrm{p}<0,01$. Dessa forma, existe uma correlação entre as 23 variáveis medidas pelos itens, logo apropriadas para a análise fatorial.

\subsection{Apresentação e discussão dos resultados}

A análise da confiabilidade foi realizada pelo método da consistência interna, com a utilização do coeficiente Alpha de Cronbach. Os três fatores formaram três subescalas precisas $(\alpha=0,923 ; 0,876$ e 0,808), aceitáveis para a confiabilidade (Sampieri, Collado e Lucio, 2013).

Para efeito de análise, os três fatores ficaram assim denominados: F1 se refere ao contexto de ensino aprendizagem na formação discente no uso da TDIC é constituído pelos itens: E1, E3, E4, E5, E8, E9, E10, E16, E19, E20, E21, E22, e E23; F2 alude ao trabalho docente na formação discente no desenvolvimento de habilidades para o uso das TDIC que é constituído pelos itens E11, E12, E13, E14, E15, E17 e E18; e F3 que faz referência ao desenvolvimento de habilidades na formação discente para o uso das TDIC ficando constituído pelos itens: E2, E6 e E7.

Em relação à amostra, foram identificados entre os respondentes que $91(77,12 \%)$ eram alunos do sexo feminino. Foi constado através de outras pesquisas que a frequência do curso de pedagogia é predominantemente feminina, sendo essa uma característica histórica e cultural do curso (MANDÚ, 2013). A autora identificou uma predominância do gênero feminino entre os participantes de uma pesquisa, sendo $93,2 \%$ estudantes do gênero feminino e apenas $6,8 \%$ do gênero masculino. Já Basílio e Machado (2013) afirmam ter achado um grupo predominantemente feminino num percentual de $95 \%$. Esses achados não só confirmam o curso de pedagogia com uma frequência predominante feminina, como mostraram resultados superiores aos encontrados nesta pesquisa. A idade dos alunos se distribui com uma média de 27,4 anos e mediana de 26 anos. O coeficiente de variação foi de $24,1 \%$, indicando que a distribuição da idade dos alunos era homogênea. O coeficiente de assimetria de 1,211 mostra uma concentração de idade abaixo da média. As idades se concentraram entre 20 e 29 anos (70,3\% da amostra de aluno).

A amostra de professores das turmas pesquisadas foi constituída por nove docentes, sendo cinco do gênero feminino $(55,6 \%)$. As idades dos nove professores da amostra variaram em 40 a 58 anos com média 49,3 anos e mediana 51 anos. O coeficiente de variação de 13,1\%, indica uma distribuição homogênea das idades. O coeficiente de 
assimetria negativo $(-0,198)$ mostrou uma pequena concentração das idades, acima da idade média.

Conforme mostrado na tabela $4,11,1 \%$ dos respondentes possuíam titulação de mestrado, 56,6\% possuíam doutorado e 33,3\% haviam feito estágio de pós-doutorado. A Tabela 4 apresenta a relação entre a formação acadêmica e o uso das TDIC na prática pedagógica. Os dados mostram que todos os professores afirmaram que usavam as TDIC na sua prática pedagógica. Com relação aos anos de formação acadêmica, a maioria dos professores com menos de 10 anos de formação acadêmica que usam as TDIC na sua prática pedagógica são doutores (33,3\%). Já os que usam as TDIC na sua prática pedagógica com mais de 10 anos de formação acadêmica são os doutores e pósdoutores, com 22,2\% cada. A partir dos resultados obtidos, pode-se inferir que os doutores estão se dedicando mais em relação ao uso das TDIC na sua prática pedagógica, e doutores com poucos anos de atividades estão mais receptíveis ao advento das TDIC no ensino superior.

Tabela 4. Comparativo entre os anos de uso de TDIC e formação acadêmica

\begin{tabular}{|c|c|c|c|c|c|}
\hline \multirow{2}{*}{\multicolumn{2}{|c|}{$\begin{array}{l}\text { ANOS DE USO DAS TDIC NA } \\
\text { PRÁTICA PEDAGÓGICA }\end{array}$}} & \multicolumn{3}{|c|}{ FORMAÇÃO ACADÊMICA } & \multirow{3}{*}{$\frac{\text { TotaL }}{5}$} \\
\hline & & \multirow{2}{*}{$\frac{\text { 3.Mestrado }}{1}$} & \multirow{2}{*}{$\begin{array}{c}\text { 4.Doutorado } \\
3\end{array}$} & \multirow{2}{*}{$\begin{array}{c}\text { 5.Pós-doc } \\
1\end{array}$} & \\
\hline & Quant. & & & & \\
\hline $\begin{array}{l}\text { que } 10 \\
\text { anos no }\end{array}$ & $\begin{array}{l}\text { Anos de uso das } \\
\text { TDIC na prática } \\
\text { pedagógica }\end{array}$ & $20,0 \%$ & $60,0 \%$ & $20,0 \%$ & $100,0 \%$ \\
\hline uso das & Formação acadêmica & $100,0 \%$ & $60,0 \%$ & $33,3 \%$ & $55,6 \%$ \\
\hline & Total & $11,1 \%$ & $33,3 \%$ & $11,1 \%$ & $55,6 \%$ \\
\hline & Quant. & $\mathrm{O}$ & 2 & 2 & 4 \\
\hline 10 anos & Anos de uso das & & & & \\
\hline $\begin{array}{l}\text { no uso } \\
\text { das }\end{array}$ & $\begin{array}{l}\text { TDIC na prática } \\
\text { pedagógica }\end{array}$ & $0,0 \%$ & $50,0 \%$ & $50,0 \%$ & $100,0 \%$ \\
\hline TDIC & Formação acadêmica & $0,0 \%$ & $40,0 \%$ & $66,7 \%$ & $44,4 \%$ \\
\hline & Total & $0,0 \%$ & $22,2 \%$ & $22,2 \%$ & $44,4 \%$ \\
\hline Mais de & Quant. & 1 & 5 & 3 & 9 \\
\hline $\begin{array}{l}10 \text { anos } \\
\text { no uso }\end{array}$ & $\begin{array}{l}\text { Anos de uso das } \\
\text { TDIC na prática } \\
\text { pedagógica }\end{array}$ & $11,1 \%$ & $55,6 \%$ & $33,3 \%$ & $100,0 \%$ \\
\hline das & Formação acadêmica & $100,0 \%$ & $100,0 \%$ & $100,0 \%$ & $100,0 \%$ \\
\hline & Total & $11,1 \%$ & $55,6 \%$ & $33,3 \%$ & $100,0 \%$ \\
\hline
\end{tabular}

Fonte: Elaboração propia.

Os resultados obtidos na pesquisa revelaram que 33,3\% dos professores com menos de 10 anos de uso das TDIC e 66,7\% com mais de 10 anos de uso das TDIC fazem uso das mesmas na sua prática pedagógica. Pode-se inferir diante desses dados que, quanto mais anos de experiência com TDIC no ensino o professor possuía, mais o mesmo estaria buscando o uso das mesmas em sua prática pedagógica.

Tomando-se as variáveis independentes nas análises de variância e correlacionando-as com a idade dos alunos (coeficiente de correlação Pearson) verificou-se que os coeficientes obtidos são muito baixos e nenhum deles é significativo, todos com nível de significância variando entre 0,10 a 0,98 , isto é, a idade do aluno não influência na forma como se responde aos itens da escala.

Para fazer a análise das expressões de discordância/concordância das percepções dos professores e alunos às afirmações polares foram utilizados os polos semânticos, conforme Pereira (2004). Tendo como base os dados obtidos a partir do cálculo das 
médias dos professores e alunos. Usando a escala de Likert de 5 pontos (0 a 4), com ponto médio igual a 2 , representando a neutralidade, delimita-se o domínio de discordância ( 0 e 1) e de concordância (3 e 4), cujo intervalos de apresentação envolveram uma grandeza de 2 pontos. A localização no campo da discordância ou concordância foi feita pela subtração da neutralidade, resultados positivos se posicionaram no campo da concordância e resultados negativos se posicionaram no campo da discordância.

O fator 1 compreende treze itens da escala de avaliação da formação do licenciando em pedagogia no uso das TDIC. Os resultados das médias do fator 1 (tabela 5) apresenta uma discordância em praticamente todos os itens do fator, com exceção dos itens E8 (Os alunos são esclarecidos sobre a importância de se trabalhar com as novas tecnologias) e E16 (O processo formativo contempla a integração com as escolas públicas de ensino básico para o uso pedagógico das TDIC), entre professores e alunos. Os professores se posicionaram no polo da concordância e o aluno no polo da discordância. Os subtemas que fazem parte desse fator são: Currículo e as TDIC (E1, E4, E20), infraestrutura (E3), Projeto Pedagógico do Curso (E5, E21 e E22), prática de ensino (E8, E9, E10, E16) e plano estratégico da instituição (E19 e E23).

A respeito da relação Projeto Pedagógico do Curso (PPC) x TDIC, os professores concordam nas suas afirmativas, e no polo extremo, os alunos discordam das duas. Os alunos discordam que a concepção do PPC incentive a integração das TDIC no currículo, já que os objetivos do curso não apresentam coerência com o perfil profissional do egresso em relação ao uso pedagógico das TDIC e também por que as TDIC disponíveis para o processo ensino aprendizagem não permitem executar o PPC de forma satisfatória. Conforme o PPC (PPC/PEDAGIOGIA/UFC, 2006) um dos objetivos do curso é "c) além dos conteúdos específicos básicos para a formação do professor, incluir conhecimentos referentes à (...) Informática na educação, Educação à distância” (p.13-14); O PPC tem entre suas finalidades com relação ao perfil do egresso em ele "reconhecer o impacto das novas tecnologias como um dos requisitos para a construção e efetivação da cidadania, assim como para a renovação da sua prática pedagógica" (p.12). A partir dos resultados obtidos pode-se inferir que essas questões necessitam ser mais bem trabalhadas com os alunos, pois a integração curricular do curso contempla de forma satisfatória o trabalho com as TDIC. Faz-se necessário, tornar mais transparente o documento oficial norteador do curso, buscando práticas que demonstrem a efetivação do que orienta o projeto pedagógico.

Os alunos discordam que a instituição possui plano estratégico para o uso das TDIC como ferramenta pedagógica e discordam também que a UFC se preocupa com o trabalho docente, levando em conta os benefícios do uso das TDIC na prática pedagógica. Infere-se que as instituições devem ficar atentas para a divulgação de seu plano estratégico, visando uma melhor transparência dos seus planos de ação e das metas que almeja alcançar durante a gestão.

O fator 2 é constituído por sete itens da escala de avaliação da formação do licenciando em pedagogia no uso das TDIC. Conforme apresentado na tabela 6, a análise do fator 2 apresentou resultados bastante heterogêneos. O item E11 apresentou média negativa dos alunos, que se posicionaram no polo da discordância e média positivas dos professores, posicionando-os no polo extremo da concordância. O item E12 apresentou uma média do professor igual à zero. Do item E14 ao E18, foram identificadas médias 
negativas, tanto de professores quanto de alunos, posicionando-os no polo de discordância. Os subtemas pertencentes a esse fator são: Trabalho docente e TDIC (itens E11, E12 e E13), articulações pedagógicas (itens E14 e E17) e avaliação (itens E15 e E18).

Tabela 5. Fator 1: Contexto de ensino aprendizagem na formação discente no uso da TDIC

\begin{tabular}{|c|c|c|}
\hline ITEM & $\begin{array}{c}\text { MÉDIA } \\
\text { PROFESSOR }\end{array}$ & MÉdiA ALUNo \\
\hline $\begin{array}{l}\text { Item E1(A estrutura curricular contempla a articulação da } \\
\text { teoria com a prática do futuro professor e as novas } \\
\text { tecnologias). }\end{array}$ & $2,78-2,00=0,78$ & $1,47-2,00=-0,53$ \\
\hline $\begin{array}{l}\text { Item E3 (Os laboratórios no campus possuem } \\
\text { infraestrutura necessária para trabalhar } \\
\text { pedagogicamente com as TDIC). }\end{array}$ & $2,89-2,00=0,89$ & $1,32-2,00=-0,68$ \\
\hline $\begin{array}{l}\text { Item E4 (As disciplinas da matriz curricular atendem os } \\
\text { objetivos do curso que buscam o trabalho com as TDIC) }\end{array}$ & $2,44-2,00=0,44$ & $1,46-2,00=-0,54$ \\
\hline $\begin{array}{l}\text { Item E5 (O projeto pedagógico do curso }[\mathrm{PPC}] \text { incentiva } \\
\text { a integração das TDIC no currículo). }\end{array}$ & $2,44-2,00=0,44$ & $1,79-2,00=-0,21$ \\
\hline $\begin{array}{l}\text { Item E8 (Os alunos são esclarecidos sobre a importância } \\
\text { de se trabalhar com as novas tecnologias). }\end{array}$ & $3, \mathrm{OO}-2, \mathrm{OO}=1, \mathrm{OO}$ & $2,31-2,00=0,31$ \\
\hline $\begin{array}{l}\text { Item E9 (As aulas são dinâmicas com o uso das mais } \\
\text { diversas mídias [impressa, TV, rádio e computador]). }\end{array}$ & $2,44-2,00=0,44$ & $1,47-2,00=-0,47$ \\
\hline $\begin{array}{l}\text { Item E10 (As aulas são enriquecidas com o uso dos } \\
\text { recursos pedagógicos da Internet). }\end{array}$ & $2,44-2,00=0,44$ & $1,92-2,00=-0,08$ \\
\hline $\begin{array}{l}\text { Item E16 (O processo formativo contempla a integração } \\
\text { com as escolas públicas de ensino básico para o uso } \\
\text { pedagógico das TDIC). }\end{array}$ & $1,78-2,00=-0,22$ & $1,51-2,00=-0,49$ \\
\hline $\begin{array}{l}\text { Item E19 (A instituição possui um plano estratégico para } \\
\text { o uso das TDIC como ferramenta pedagógica). }\end{array}$ & $2,11-2,00=0,11$ & $1,46-2,00=-0,54$ \\
\hline $\begin{array}{l}\text { Item E 20. (A instituição preocupa-se com os benefícios do } \\
\text { uso das TDIC no currículo). }\end{array}$ & $2,78-2,00=0,78$ & $1,61-2,00=-0,39$ \\
\hline $\begin{array}{l}\text { Item E } 21 \text { (Os objetivos do curso apresentam coerência } \\
\text { com o perfil profissional do egresso com relação ao uso } \\
\text { pedagógico das TDIC). }\end{array}$ & $2,44-2,00=0,44$ & $1,56-2,00=-0,44$ \\
\hline $\begin{array}{l}\text { Item E } 22 \text { (As TDIC disponíveis para o processo ensino } \\
\text { aprendizagem permitem executar o PPC de forma } \\
\text { satisfatória). }\end{array}$ & $2,44-2,00=0,44$ & $1,41-2,00=-0,59$ \\
\hline $\begin{array}{l}\text { Item E } 23 \text { (A instituição preocupa-se com o trabalho } \\
\text { docente levando em conta os benefícios do uso das } \\
\text { TDIC na sua prática pedagógica). }\end{array}$ & $2,56-2,00=0,56$ & $1,51-2,00=-0,49$ \\
\hline
\end{tabular}

Fonte: Elaboração própria.

Os resultados revelam que os professores respondentes afirmaram fazer uso das TDIC na sua prática, entretanto, na observação simples do pesquisador, foi identificado somente o uso das seguintes tecnologias digitais: notebook ou netbook, mídias digitais (DVD) e o projetor de slides (Datashow). O uso de tais instrumentos não configura um trabalho pedagógico com uso das TDIC, mas somente a troca de uma ferramenta (por exemplo, giz e apagador) por outra. Dessa forma, não se demonstrou, portanto, uma mudança de postura pedagógica.

O resultado sobre o trabalho docente com o uso das tecnologias digitais livres, ficou no polo da discordância, tanto de professores quanto de alunos. Os resultados indicaram que as tecnologias digitais livres ainda não constam na prática docente dos formadores de futuros professores. As articulações pedagógicas que poderiam ser favorecidas com 
uso das TDIC também ficaram no polo da discordância dos professores e dos alunos. Diante das afirmações, os respondentes foram categóricos em discordar que o software livre possui um papel cada vez mais importante nas estratégias de uso pedagógico com as TDIC e que o curso relaciona as políticas públicas governamentais, que são direcionadas ao uso pedagógico das TDIC, com seu PPC, propiciando ao aluno habilidades necessárias para trabalhar com essas ferramentas em sua prática pedagógica.

A análise desse fator demonstra a fragilidade da formação do futuro professor para o uso pedagógico das TDIC, mostrando pontos falhos na prática do docente formador, a ausência de articulações com as políticas públicas que envolvem as TDIC, a falta do que se objetiva, mas não acontece na prática e a inexistência de um processo avaliativo do aluno (tabela 6).

Tabela 6. Fator 2: Trabalho docente na formação discente no desenvolvimento de habilidades para o uso das TDIC

\begin{tabular}{|c|c|c|}
\hline ITEM & $\begin{array}{c}\text { MÉDIA } \\
\text { PROFESSOR }\end{array}$ & MÉDIA ALUNO \\
\hline $\begin{array}{l}\text { Item E } 11 \text { (O corpo docente se mostra sensível ao uso } \\
\text { das TDIC na sua prática pedagógica, fazendo uso } \\
\text { delas no seu dia a dia acadêmico). }\end{array}$ & $2,56-2,00=0,56$ & $1,95-2,00=-0,05$ \\
\hline $\begin{array}{l}\text { Item E } 12 \text { (O corpo docente está bem preparado para } \\
\text { usar as TDIC como recurso para as atividades de } \\
\text { ensino e aprendizagem na educação básica). }\end{array}$ & $2,00-2,00=0,00$ & $1,50-2,00=-0,50$ \\
\hline $\begin{array}{l}\text { Item E } 13 \text { (O trabalho docente do curso é voltado para } \\
\text { o uso das tecnologias digitais livres). }\end{array}$ & $1,33-2,00=-0,67$ & $1,46-2,00=-0,54$ \\
\hline $\begin{array}{l}\text { Item E } 14 \text { (No curso, o software livre tem um papel } \\
\text { cada vez mais importante nas estratégias de uso } \\
\text { pedagógico com as TDIC). }\end{array}$ & $1,56-2,00=-0,44$ & $1,81-2,00=-0,19$ \\
\hline $\begin{array}{l}\text { Item E } 15 \text { (Os alunos do curso são avaliados } \\
\text { processualmente com relação ao uso das TDIC na } \\
\text { educação). }\end{array}$ & $1,89-2,00=-0,11$ & $1,31-2,00=-0,69$ \\
\hline $\begin{array}{l}\text { Item E } 17 \text { (O curso relaciona as políticas públicas } \\
\text { governamentais que são direcionadas ao uso } \\
\text { pedagógico das TDIC com seu PPC, propiciando ao } \\
\text { aluno habilidades necessárias para trabalhar com } \\
\text { essas ferramentas em sua prática pedagógica). }\end{array}$ & $1,78-2,00=-0,22$ & $1,47-2,00=-0,53$ \\
\hline $\begin{array}{l}\text { Item E } 18 \text { (O curso contribui na elaboração de } \\
\text { instrumentos de avaliação do ensino-aprendizagem } \\
\text { com uso das TDIC para a educação básica). }\end{array}$ & $1,89-2,00=-0,11$ & $1,41-2,00=-0,59$ \\
\hline
\end{tabular}

O fator 3 é composto por três itens da escala de avaliação da formação do licenciando em pedagogia no uso das TDIC. Os resultados das médias do fator 3 apresentara uma concordância em todos os itens, entre professores e alunos (tabela 7). Os subtemas que compõem o fator são: aquisição de habilidades para o trabalho com as TDIC (itens E2 e E6) e adquirir conhecimento básico de informática (item E7). Esse fator foi fortemente aprovado tanto pelos alunos, como pelos professores. Foi o único fator onde as médias dos alunos foram superiores à dos professores. Isso indica que a comunidade universitária está ciente da importância de se aprender a utilizar as ferramentas básicas de informática, bem como de adquirir habilidades para se trabalhar pedagogicamente com as TDIC. 
Tabela 7. Fator 3: Desenvolvimento de habilidades na formação discente

\begin{tabular}{|c|c|c|}
\hline ITEM & $\begin{array}{c}\text { MÉDIA } \\
\text { PROFESSOR }\end{array}$ & MÉDIA ALUNO \\
\hline $\begin{array}{l}\text { Item E2 (É importante que o futuro professor adquira } \\
\text { habilidades necessárias para trabalhar com as novas } \\
\text { tecnologias na educação). }\end{array}$ & $3,56-2,00=1,56$ & $3,75-2,00=1,76$ \\
\hline $\begin{array}{l}\text { Item E6 (Adquirir habilidades necessárias para trabalhar } \\
\text { com as TDIC são importantes, pois oferece grandes } \\
\text { benefícios para a formação dos alunos). }\end{array}$ & $3,22-2,00=1,22$ & $3,59-2,00=1,59$ \\
\hline $\begin{array}{l}\text { Item E7 (O futuro professor deve aprender a utilizar as } \\
\text { ferramentas básicas de Informática, possibilitando o } \\
\text { desenvolvimento de habilidades para o enriquecimento da } \\
\text { Prática Pedagógica). }\end{array}$ & $3,67-2,00=1,67$ & $3,79-2,00=1,79$ \\
\hline
\end{tabular}

\section{Considerações finais}

$\mathrm{O}$ uso de computadores pode ser visto como um recurso auxiliar no processo educacional e jamais como um fim em si mesmo. Esse suporte deveria vir a partir do desenvolvimento da inteligência do aluno, possibilitando o desenvolvimento de habilidades intelectuais requeridas para os conteúdos específicos nas diversas disciplinas. As habilidades a serem adquiridas deveriam iniciar a partir da educação básica, sem restrições. Busca-se incorporar o uso de TDIC na educação básica Brasileira.

No presente trabalho, foram comparadas as percepções dos discentes e docentes sobre o contexto de ensino e aprendizagem do curso de pedagogia da UFC, averiguando se a prática dos docentes favorecia o desenvolvimento de habilidades e competências necessárias para a formação de professores aptos para a prática pedagógica com o uso das tecnologias digitais.

Constatou-se durante a revisão da literatura, principalmente no trabalho de Gatti e Barreto (2009), que as instituições de ensino estão incluindo em suas matrizes curriculares disciplinas voltadas para o uso das tecnologias digitais, mesmo que de forma tímida. Essas disciplinas, em alguns casos, são optativas, o que demonstra a falta de prioridade em relação à importância das TDIC na educação. Pode-se inferir que talvez essa falta de prioridade aconteça por mera formalidade recomendada pelas leis em vigor.

$\mathrm{O}$ uso das TDIC no currículo de formação de professores deve perpassar de forma transversal todas as disciplinas, articulando naturalmente as diversas formas de intervenção na aprendizagem. $\mathrm{O}$ desenvolvimento das TDIC vem causando transformações em todas as áreas da sociedade. O computador, assim como as demais mídias digitais (smartfone, tablet, etc) tem demonstrado um grande potencial para colaboração nas mudanças que vem ocorrendo na educação. Dessa forma, se faz necessário a preparação dos professores para o uso pedagógico das TDIC, tendo em vista que a educação em todos seus níveis não deve ficar alheia aos avanços tecnológicos. Os futuros professores devem ser preparados para enfrentar os desafios atuais de uma sociedade em constante mudança. Para tanto, torna-se essencial que aconteçam mudanças significativas na elaboração e execução de cursos que abordem especificamente a formação de professores.

O presente trabalho apresenta uma contribuição para a melhoria da qualidade na formação do pedagogo para a utilização de TDIC, a partir da revisão de literatura, da 
avaliação e discussão dos resultados apresentados. Tais resultados podem ser utilizados no desenvolvimento de novas estratégias para utilização de TDIC pelos pedagogos que irão atuar no ensino básico, médio e na formação de jovens e adultos.

Devido ao fato deste estudo ter sido realizado especificamente em um curso de graduação de uma Universidade Brasileira, pode haver alguma dificuldade na generalização dos resultados. Entretanto, apesar de preliminares, os resultados obtidos se mostraram importantes, sólidos e confiáveis.

Como trabalho futuro, espera-se avaliar a formação do pedagogo no uso das TDIC em outras Instituições públicas e privadas, em um estudo comparativo.

\section{Referências}

Almeida M. E. B. (2004). Inclusão digital do professor: formação e prática pedagógica. São Paulo: Articulação.

Bisquerra, R. (2004). Metodología de la investigación educativa. Madrid: La Muralla.

Borges Neto H. (abril, 1998). Uma classificação sobre a utilização do computador pela escola. Comunicação apresentado no IX ENDIPE-Encontro Nacional de Didática e Prática de Ensino. Universidade de São Paulo.

Botello Álvarez, J., Chaparro Salinas E. M. e Reyes Pérez D. E. (2015). Estudio de la Satisfacción de los Estudiantes con los Servicios Educativos brindados por Instituciones de Educación Superior del Valle de Toluca, REICE. Revista Iberoamericana sobre Calidad, Eficacia y Cambio en Educación, 13(2), 5-26.

Bustamante J. (2010). Poder Comunicativo, ecossistemas digitais e cidadania digital. En S. Silveira (Ed.), Cidadania e Redes Digitais. Citizenship and digital (pp. 98-138). São Paulo: Comitê Gestor da Internet no Brasil.

Catapan, A., Colauto R. D. e Sillas E. P. (2012). Percepção dos discentes sobre os docentes exemplares de contabilidade em IES públicas e privadas. Revista de Informação Contábil, $6(2), 63-82$.

Carlos Gil, A. (1999). Métodos e técnicas da pesquisa social. São Paulo: Editora Atlas.

Castro, M. S. F. (2012). Desenvolvimento da criatividade no ensino superior. Avaliação dos cursos do Instituto de Cultura e Arte da Universidade Federal do Ceara (UFC). Tesis Doctoral. Universidade Federal do Ceará, Brasil.

Coracini, E. G. R. (2010). A formação de professores para o uso das tecnologias digitais nos cursos de pedagogia. Tesis Doctoral. Universidade do Estado de Santa Catarina, Brasil.

Costa J. W., Guimarães M. B. M. e Grossi M. G. R. (2013). Concepção construtivista permeada pelo uso de tecnologias: um estudo de caso. Revista Ibero Americana de Estudos em Educação, 8(12), 378-393.

Da Silva W. P. (2013). O uso das novas tecnologias da informação e comunicação na promoção do trabalho docente. Recuperado de http://bdm.unb.br/handle/10483/8995

Freitas A. V. e Leite L. S. (2013). Tecnologias digitais na formação continuada do professor da rede estadual do Rio de Janeiro: impactos e desafios. Revista de Educação, Ciências e Matemática, 3(1), 34-54.

Hair, J. F. (2006). Análise multivariada de dados. Porto Alegre: Arteme 
Kerlinger, F. e Lee, H. B. (2002). Investigación del comportamiento: métodos de investigación en ciencias sociales. México: McGraw Hill.

Kruger S. E. (2006). Educação musical apoiada pelas novas tecnologias de informação e comunicação: pesquisas, práticas e formação de docentes. Revista da ABEM, 14, 75-89.

Lima A. S. e Andriola W. B. (2013). Avaliação de práticas pedagógicas inovadoras em curso de graduação em sistemas de informação. REICE. Revista Iberoamericana sobre Calidad, Eficacia y Cambio en Educación, 11(2), 104-121.

Maia D. L. e Barrreto M. C. (2014). Ensinar Matemática com o uso de tecnologias digitais: uma análise a partir da representação social de estudantes de Pedagogia. Revista Educação e Cultura Contemporânea, 11(24), 56-79.

Monteiro, A. M. (2011). Pesquisa em pós-graduação em educação e a formação de professores: tensões e desafios curriculares no tempo presente. Recuperado de: http://www.fe.ufrj.br/anpedinha2011/ebook2.html.

Morales, P. (2010). Investigación e innovación educativa. REICE. Revista Iberoamericana sobre Calidad, Eficacia y Cambio en Educación, 8(2), 47-73.

Pereira, J. (2004). Análise de dados qualitativos: estratégias metodológicas para as ciências da saúde, humanas e sociais. São Paulo: Editora da Universidade de São Paulo.

Rodrigues, E. e Bilessimo, S. M. S. (2012). Inovação na prática docente: uso das tecnologias digitais nas aulas de cálculo em uma IES catarinense. Seminário de Ciências Sociais Aplicadas, 3(3), 17-33.

Sampieri R. H., Collado C. F. e Lucio M. P. B. (2013). Metodologia de pesquisa. Porto Alegre: Penso Editora

Sánchez Ramón, J. M. (2005). La innovación educativa institucional y su repercusión en los centros docentes de Castilla-La Mancha. REICE. Revista Iberoamericana sobre Calidad, Eficacia y Cambio en Educación, 3(1), 637-664.

Saviani, D. (2005). História da formação docente no Brasil: três momentos decisivos. Revista Educação, 30(2), 114-132.

Valente, J. A., Prado M. E. e Almeida M. E. B. (2003). Educação à distância via internet. São Paulo: Avercamp.

Vieira, S. (2009). Como elaborar questionários. São Paulo: Atlas.

\title{
Breve CV de los autores
}

\begin{abstract}
Alberto Sampaio Lima
Doutor em Engenharia de Teleinformática pela Universidade Federal do Ceará. Mestre em Informática Aplicada pela Universidade de Fortaleza. Bacharel em Ciência da Computação pela Universidade Estadual do Ceará. Tem experiência na área de Ciência da Computação, com ênfase em Arquitetura de Sistemas de Computação, atuando principalmente nos seguintes temas: Gestão de Tecnologia da Informação e Comunicação, Redes de Computadores, Engenharia de Software, Novas Tecnologias na Educação, Avaliação da Educação. Professor do Mestrado Profissional em Políticas Públicas e Gestão da Educação Superior da Universidade Federal do Ceará. Email: albertosampaio@ufc.br
\end{abstract}




\section{Wagner Bandeira Andriola}

Possui graduação em Psicologia pela Universidade Federal da Paraíba (1990), especialização (lato sensu) em Psicometria pela Universidade de Brasília (1992), mestrado em Psicologia pela Universidade de Brasília (1993 - bolsista CNPq) e doutorado em Filosofia e Ciências da Educação pela Universidad Complutense de Madrid (2002 - bolsista CAPES). Atualmente é Professor Associado da Universidade Federal do Ceará (UFC), Coordenador de Avaliação Institucional (UFC), Editor-Chefe da Coleção Temas em Avaliação Educacional, do Programa de Mestrado e Doutorado em Educação (UFC) e Bolsista de Produtividade em Pesquisa (CNPq). Tem experiência nas áreas de Psicologia e de Educação, com ênfase em Avaliação de Sistemas, Instituições, Planos e Programas Educacionais, atuando principalmente nos seguintes temas: avaliação institucional, avaliação psicológica, psicometria e avaliação de programas e projetos sociais. Consultor ad-hoc da Revista Ensaio: Avaliação de Políticas Públicas em Educação (CESGRANRIO), da Revista Psicologia: Reflexão e Crítica (UFRGS), da Revista de Avaliação Psicológica (IBAP) e da Revista Psicologia: Teoria e Pesquisa (UnB); Consultor ad hoc do Conselho Nacional de Desenvolvimento Científico e Tecnológico (CNPq), da Coordenação de Aperfeiçoamento de Pessoal de Nível Superior (CAPES), da Fundação Cearense de Apoio Científico e Tecnológico (FUNCAP). Membro da Diretoria da Associação Nacional de Avaliação Educacional (ABAVE - Gestões 2006/2007 e 2008/2009), da Red Iberoamericana de Investigación sobre Cambio y Eficacia Escolar (RINACE) e do Grupo de Trabalho para Elaboración de Estandares y Evaluación del Programa de Promoción de la Reforma Educativa de América Latina y el Caribe (PREAL). Ex-bolsista de Desenvolvimento Científico e Regional (DCR) do CNPq. Email: w_andriola@ufc.br

\section{Francisco César Martins da Silva}

Professor do Instituto Federal do Ceará (IFCE). Mestre em Políticas Públicas e Gestão da Educação Superior. Pedagogo. Possui experiência profissional como docente no ensino básico e médio. Email: profcesarmartins2012@gmail.com 